How to cite: Üneş, F., Demirci, M., Varçin, H. (2019) Wall Jet Flow Simulation in a Reservoir Using a ThreeDimensional Mathematical Model. 2019 "Air and Water - Components of the Environment" Conference Proceedings, Cluj-Napoca, Romania, p. 247-260, DOI: 10.24193/AWC2019_25.

\title{
WALL JET FLOW SIMULATION IN A RESERVOIR USING A THREE-DIMENSIONAL MATHEMATICAL MODEL
}

\author{
Fatih ÜNEŞญ, Mustafa DEMİRCI, Hakan VARÇİN
}

DOI: 10.24193/AWC2019_25

\begin{abstract}
Density and divergence flow analysis in a dam reservoir is essential from the point of view of reservoir sedimentation studies, water quality modeling, habitat in reservoirs, effluent mixing analyses, and circulation flows in ambient waters of a dam. In the present study, different density inflow was modeled in three-dimensions along a dam reservoir with diverging and sloping bottom channels. Nonlinear and unsteady continuity, momentum, energy and turbulence model equations were formulated in the Cartesian coordinates. k- $\varepsilon$ turbulence model including density effects was used to the turbulence viscosity. The Coriolis force effect was also included in the governing equations for a dam reservoir. The generated model was solved based on the initial and boundary conditions of the dam reservoir flow for a range of bottom slopes and divergence angles. The model successfully simulates the formation of wall jets in ambient water. The present model simulation results were compared with previous experimental work. The present model results were compatible with the experimental results.
\end{abstract}

Keywords: Dam reservoir, Mathematical model, Density flow, Wall jet flow, Divergence flow

\section{INTRODUCTION}

Nowadays, a new master project includes consecutive dam construction and one dam outflow creates inflow in another dam, as seen Fig. 1 (Üneş, 2010). Therefore, the important issue in these types of projects is to define an accurate thermal stratification flow and take precautions. Previous studies from field and laboratory practice have shown that small temperature differences are enough to produce density flow in the reservoir. And also, the density difference in a reservoir may be due to differences in concentration of dissolved or suspended substances, temperature or a combination of both.

When inflow river water enters a quiescent dam reservoir waters, three basic types of currents may occur. These flows are called the over-flow; inter-flow, and density plunging or turbidity current flow. If density of incoming flow is smaller than quiescent water body in the reservoir, the flow resulting from this will move along the free surface and is called over-flow. When reservoir quiescent water is stratified due to temperature or other effects, inflow river water will go forward an

1 Iskenderun Technical University, Eng. Faculty, Civil Eng Department, TURKEY fatihunes66@gmail.com mustafa.demirci@iste.edu.tr hakan.varcin@iste.edu.tr 
intermediate layer that density of this flow layer is equal to inflow density. This flow is called inter-flow. However, if inflow river water density is denser than quiescent water density of dam reservoir, then this type of flow will plunge below the ambient water and will move along the reservoir bottom. This flow type is named plunging flow, underflow, or density negatively buoyant flow. However, Real dam reservoirs do not always have typical geometry due to variation in volume and shape. If river inflow enters a reservoir in a narrow valley, inflow may have little divergence and more slope effect but if it runs to a reservoir in a wide valley, of course, both inflow and plunging flow may affect divergence Farrell and Stefan (1988). Such dam reservoir dimension features may lead to incomplete lateral mixing of the inflow. Therefore, the geometry of dam reservoir at the point of discharge entrance also plays an important role in the formation of the plunge and the subsequent evolution of the underflow. However, density current is a quantity that is very difficult to measure in field and also laboratory experiments.

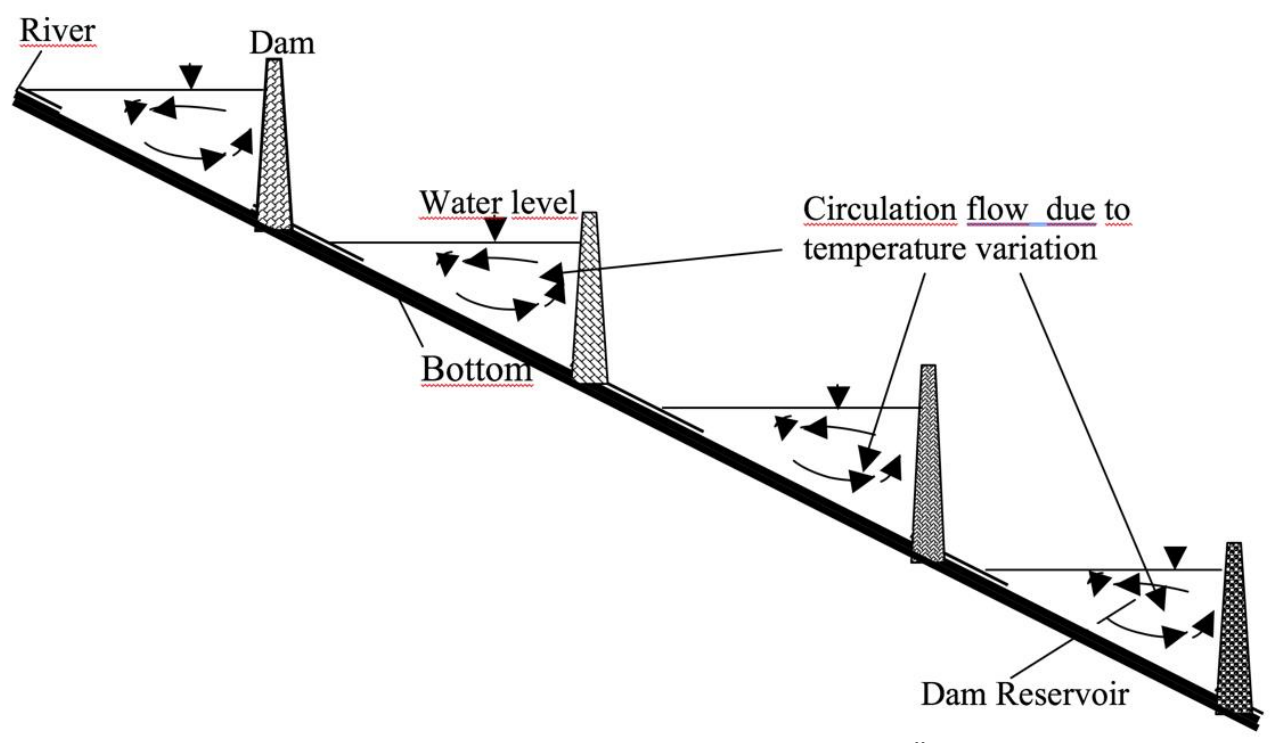

Fig. 1. Schematic figure of consecutive dams (Üneş, 2010)

Although, most of the data available are from flume tests in laboratory, such experimental work is not sufficient to understand the longitudinal developments of the hydraulic characteristics of density flows over a long distance. On the other hand, mathematical models can give more information about density flow characteristics over the entire dam reservoir (Üneş, 2008b).

In the past studies, density and plunging flow has been evaluated theoretical using simple models such as two-layer approach. These approaches concentrate attention on the plunge region only and effectively isolate the plunge region from the rest of the reservoir. Because reservoir flow or density flows process is developed based on hydrodynamic rules throughout the reservoir length, flows are not divided into portions such as plunging region, underflow region and ambient water in real dam 
reservoir. The analysis of all flow in the reservoir is essential from the point of view of reservoir sedimentation management, water quality modeling, sedimentation studies, and turbidity flow analysis and also important in defining of formation of separated flows such as wall-jet and free-jet flows.

Density currents have been studied using semi empirical model and laboratory experiments by many researchers (Singh and Shah, 1971; Savage and Brimberg, 1975; Akiyama and Stefan, 1984; Alavian, 1986; Farrell and Stefan, 1988). Johnson and Stefan (1988) and Farrell and Stefan (1988) studied negatively buoyancy flow in diverging channel with experimental. In addition, many researchers have investigated the problem by solving it using numerical methods (Farrell and Stefan, 1988; Fukushima and Watanabe, 1990; Bournet et al., 1999; Kassem and Imran, 2001; Kassem et al., 2003, Üneş, 2004, 2005; Üneş and Ağıralioğlu, 2004; Varçin and Üneş, 2008; Üneş, 2008a-2008b; Üneş, 2009; Üneş, 2010; Üneş et al., 2012; Üneş and Varçin, 2012; Üneş and Varçin, 2015; Üneş et al., 2016; Üneş and Varçin, 2017; Üneş and Ağıralioğlu, 2017).

Density flow and especially wall jet flows; the complexity of the subject matter is unsteady and nonlinear due to the effect of more parameters on the event, and has been studied by very few people in the past. Therefore, there is very limited laboratory study. In this study, density flow and divergence (diffuser) flow is investigated with simulation results. The model results are compared with experimental data. The present model is applied to condition of attached flow.

\section{APPLIED STUDY}

Reservoir geometry, various extraneous forces or factors such as turbidity of flow, sediment load, wind, industrial outlets, and temperature changes from seasonal and external factors can exert an influence on the density and stratified flow dynamics. For example, if density differences are due to suspended materials in addition to temperature, stratified flow, plunging flow dynamics and buoyancy flux characteristics may change.

Since dam reservoir volumes have been recently constructed very big and long dimensions, fluid particle into the reservoir is affected by the rotation of the earth at different speeds in different parts depending on their distance from the earth's axis. Therefore, when the dam reservoir flows are considered as a whole, the Coriolis force effect should be added in the model, despite its effect little compared to the other forces. In this respect, if real reservoir conditions want to be obtained, the dam reservoir is investigated by using the mathematical model including Coriolis force. But FLUENT software does not incorporate Coriolis effect. So a user define function is written. (Üneş ,2004, Üneş, 2008a-2008b; Üneş, 2009; Üneş, 2010; Üneş et al., 2012; Üneş and Varçin, 2012; Üneş and Varçin, 2015; Üneş et al., 2015)

In this paper, negatively plunging flow is investigated with sloping reservoir bed both longitudinally and width through the reservoir. Model solutions were obtained for flows corresponding to both the experimental runs range of Johnson and Stefan (1987 a-b). Based on the initial and boundary conditions of the reservoir flow, 
present model equations are solved using control volume concept with computational fluid dynamic solver, ANSYS FLUENT software program. In model simulations, it is assumed that density flows occur only due to differences in temperatures of ambient water and inflow water.

\section{MATHEMATICAL MODEL}

The reservoir configuration is located in three dimensional, $\mathrm{x}, \mathrm{y}$ and $\mathrm{z}$, Cartesian coordinates. The experimental reservoir configuration of Johnson and Stefan (1987 $a-b)$ is used herein for mathematical model simulation.

Negative flow through a dam reservoir is a very complicated phenomenon and hard to solve. Therefore, some simplification process has to be made before presenting the governing equations. One of them, the free surface phenomenon such as wind or wave effect are not being considered in reservoir surface, and the free surface of the reservoir is modeled as rigid lid in the present model simulation. Another simplification is that the temperature difference is taken to be the source of the stratified and buoyancy flow. And suspended or dissolved substances effects are neglected on density differences.

From field and practice, small temperature differences are enough to produce density flow in the reservoir, Farrell and Stefan (1988). Therefore, the densitytemperature relation can be linearized and written as follows:

$$
\rho=\Delta \rho+\rho_{0}=\beta \rho_{0}\left[T_{0}-T\right]
$$

where, $\quad \rho$ is the water density,

$\mathrm{T}$ is the water temperature and

$\beta$ is the coefficient of thermal expansion and is calculated as

$\beta=-(\Delta \rho / \rho o)(1 / \Delta \mathrm{T})$,

where $\quad \Delta \mathrm{T}$ is the temperature difference between ambient and inflow river waters,

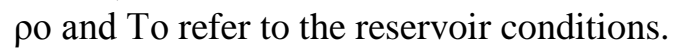

Equation (3) will be substituted into the momentum equation. If density variation is not large, " $(\Delta \rho / \rho))$ " is neglected part of multiplier in temporal and convective terms in the momentum equations, this process is called as "Boussinesq approximation". Reduced pressure, $\mathrm{P}^{\prime}=\mathrm{P}-\rho_{\mathrm{o}} \mathrm{gy}$, approach is also considered another simplification in this work. This relationship is meaningful only when the rigid lid assumption is used (Üneş, 2004, Üneş, 2008a-2008b).

If all of the previous processes are applied, then the governing equations of the mathematical model can be written in three dimensions along the horizontal, width and vertical axes in Cartesian coordinates. The mathematical model consists of the following equations;

\subsection{Continuity equation}

$$
\frac{\partial \rho}{\partial t}+\frac{\partial(\rho \bar{u})}{\partial x}+\frac{\partial(\rho \bar{v})}{\partial y}+\frac{\partial(\rho \bar{w})}{\partial z}=0
$$




\subsection{Momentum equations}

For the $\mathrm{x}$ axis,

$$
\frac{\partial \bar{u}}{\partial t}+\bar{u} \frac{\partial \bar{u}}{\partial x}+\bar{v} \frac{\partial \bar{u}}{\partial y}-\bar{w} \frac{\partial \bar{u}}{\partial z}-f \bar{v}=-\frac{1}{\rho_{o}} \frac{\partial \overline{\bar{P}}}{\partial x}+v_{e f f}\left(\left(\frac{\partial^{2} \bar{u}}{\partial x^{2}}+\frac{\partial^{2} \bar{u}}{\partial y^{2}}+\frac{\partial^{2} \bar{u}}{\partial z^{2}}\right)+\left(\frac{\partial^{2} \bar{u}}{\partial x^{2}}+\frac{\partial^{2} \bar{v}}{\partial x \partial y}+\frac{\partial^{2} \bar{w}}{\partial x \partial z}\right)\right)
$$

for the y axis,

$$
\frac{\partial \bar{v}}{\partial t}+\bar{u} \frac{\partial \bar{v}}{\partial x}+\bar{v} \frac{\partial \bar{v}}{\partial y}+\bar{w} \frac{\partial \bar{v}}{\partial z}+f \bar{u}=-\frac{1}{\rho_{o}} \frac{\partial \overline{\bar{P}}}{\partial y}+v_{e f f}\left(\left(\frac{\partial^{2} v^{2}}{\partial x^{2}}+\frac{\partial^{2} v^{-}}{\partial y^{2}}+\frac{\partial^{2} \bar{v}}{\partial z^{2}}\right)+\left(\frac{\partial^{2} \bar{u}}{\partial y \partial x}+\frac{\partial^{2} \bar{v}}{\partial y^{2}}+\frac{\partial^{2} \bar{w}}{\partial y \partial z}\right)\right)
$$

and for the $\mathrm{z}$ axis,

$$
\frac{\partial \bar{w}}{\partial t}+\bar{u} \frac{\partial \bar{w}}{\partial x}+\bar{v} \frac{\partial \bar{w}}{\partial y}+\bar{w} \frac{\partial \bar{w}}{\partial z}=-\frac{1}{\rho_{o}} \frac{\partial \bar{P}}{\partial y}+v_{e f f}\left(\left(\frac{\partial^{2} \bar{w}}{\partial x^{2}}+\frac{\partial^{2} \bar{w}}{\partial y^{2}}+\frac{\partial^{2} \bar{w}}{\partial z^{2}}\right)+\left(\frac{\partial^{2} \bar{u}}{\partial z \partial y}+\frac{\partial^{2} \bar{v}}{\partial z \partial y}+\frac{\partial^{2} \bar{w}}{\partial z^{2}}\right)\right)+g \beta\left(T_{o}-\bar{T}\right)
$$

\subsection{Energy equation for the temperature}

$$
\frac{\partial \bar{T}}{\partial t}+\bar{u} \frac{\partial \bar{T}}{\partial x}+\bar{v} \frac{\partial \bar{T}}{\partial y}+\bar{w} \frac{\partial \bar{T}}{\partial z}+f \bar{u}=\alpha_{e f f}\left(\frac{\partial^{2} \bar{T}}{\partial x^{2}}+\frac{\partial^{2} \bar{T}}{\partial y^{2}}+\frac{\partial^{2} \bar{T}}{\partial z^{2}}\right)
$$

where $\quad \bar{u}$ and $\bar{v}$ are the mean velocities in the $\mathrm{x}$ and $\mathrm{y}$ directions, respectively, $\rho$ is the water density, $\overline{\bar{P}}=\overline{P^{\prime}}+\rho k(2 / 3)$,

$\overline{P^{\prime}}$ is the mean pressure adjusted to absorb the hydrostatic portion of the gravity terms,

$\mathrm{k}$ is turbulent kinetic energy and

$\overline{\mathrm{T}}$ is the mean temperature,

$v$ eff $=v+v t$,

where $\quad v$ is the kinematics viscosity and

$v t$ is the kinematics eddy (turbulence) viscosity; and

$\alpha e f f=(v / \operatorname{Pr})+(v t / \sigma t)$ is effective thermal diffusivity coefficient;

where $\quad P r$ and $\sigma t$ are the Prandtl and turbulent Prandtl numbers, respectively.

\section{4. $\mathrm{k}-\varepsilon$ turbulence model equations}

The effect of turbulence is simulated using the modified standard $k-\varepsilon$ turbulence model including the suitable buoyancy terms. $\mathrm{k}-\varepsilon$ transport model equations have been implemented by Rodi (1980 - 1987). In the present study, FLUENT is used to solve buoyancy-extended k- $\varepsilon$ turbulence model equations proposed by Rodi (1980). Standard $\mathrm{k}-\varepsilon$ model in the program is a semi-empirical model of Launder and Spalding (1972 1974) based on model transport equations for turbulent kinetic energy (k) and its dissipation rate ( $(\varepsilon)$. In the derivation of the $\mathrm{k}-\varepsilon$ model, it was assumed that the flow is fully turbulent. The effects of molecular viscosity are negligible. The standard k- $\varepsilon$ model is valid only for fully turbulent flows. For a three-dimensional unsteady flow at the sloping bottom reservoir, the eddy viscosity vt is computed from the following equation,

$$
v_{t}=C_{\mu} \frac{k^{2}}{\varepsilon}
$$

where

$\mathrm{k}$ is the turbulent kinetic energy and

$\varepsilon$ is the turbulent energy dissipation rate per unit mass. 
$\mathrm{k}$ and $\varepsilon$ are obtained from the solution of the following equations in threedimensional flow.

Equation of $\mathrm{k}$

$\frac{\partial k}{\partial t}+\bar{u}_{j} \frac{\partial k}{\partial x_{j}}=\frac{\partial}{\partial x_{j}}\left[\left(v+\frac{v_{t}}{\sigma_{k}}\right) \frac{\partial k}{\partial x_{j}}\right]+\operatorname{Prod}+G-\varepsilon$

and equation of $\varepsilon$,

$\rho \frac{\partial \varepsilon}{\partial t}+\bar{u}_{j} \frac{\partial \varepsilon}{\partial x_{j}}=\frac{\partial}{\partial x_{j}}\left[\left(v+\frac{v_{t}}{\sigma_{\varepsilon}}\right) \frac{\partial \varepsilon}{\partial x_{j}}\right]+C_{1 \varepsilon} \frac{\varepsilon}{k} \operatorname{Prod}-C_{2 \varepsilon} \frac{\varepsilon^{2}}{k}+C_{1 \varepsilon} C_{3} \frac{\varepsilon}{k} G$

where Pr od is the production of turbulent kinetic energy from the mean flow and is given as

$$
\operatorname{Pr} o d=v_{t}\left(\frac{\partial \bar{u}_{i}}{\partial x_{j}}+\frac{\partial \bar{u}_{j}}{\partial x_{i}}\right) \frac{\partial \bar{u}_{i}}{\partial x_{j}}
$$

In these equations, $\mathrm{G}$ is the production or destruction of turbulent kinetic energy by buoyancy forces and is given as

$G=g_{i} \beta \frac{v_{t}}{\sigma_{t}} \frac{\partial \bar{T}}{\partial x_{i}}$

where, $\beta$ is thermal expansion coefficient. In addition, the values of the coefficients $\mathrm{C} \mu, \mathrm{C} 1 \varepsilon, \mathrm{C} 2 \varepsilon, \mathrm{C} 3, \sigma \mathrm{k}, \sigma \varepsilon$ and $\sigma \mathrm{t}$ appearing in the $\mathrm{k}-\varepsilon$ turbulence model equations used herein were given the standard values recommended by Launder and Spalding (1974). For the standard k- $\varepsilon$ model, these constants are taken as $\mathrm{C} \mu=0.09, \mathrm{C} 1 \varepsilon=1.44, \mathrm{C} 2 \varepsilon=$ $1.92, \sigma \mathrm{k}=1.00, \sigma \varepsilon=1.3$, and $\sigma \mathrm{t}=0.9$. In the $\mathrm{k}-\varepsilon$ model, the degree of $\varepsilon$ is determined by the constant $\mathrm{C} 3$. In the FLUENT program, the constant $\mathrm{C} 3$ is not stable value, but is instead calculated according to $\mathrm{C} 3=\tanh |\mathrm{w} / \mathrm{u}|$, where $\mathrm{w}$ is the component of the flow velocity parallel to the gravitational vector and $u$ is the component of the flow velocity perpendicular to the gravitational vector. Further details and solution procedure can be found at the ANSYS FLUENT user's guide (2006).

\subsection{Boundary and Initial Conditions}

Since reservoir density flow is unsteady and turbulence flow, flow field boundary conditions must be specified individually on the reservoir inlet and outlet planes, at the walls and at the free surface. Moreover, initial fields for each variable must also be specified. So, for each variable, boundary and initial conditions must be chosen individually.

Velocity is given a symmetry condition at the free surface. At the reservoir bottom and dam face, velocities are determined using the standard wall function that is based on the proposal of Launder and Spalding (1974). This function assumes a log-law velocity profile near the wall and is provided in ANSYS FLUENT as follows;

$$
\frac{u_{p}}{u_{*}}=\frac{1}{K} \ln \left(E \frac{u_{*} y_{p}}{v}\right)-\Delta B
$$

where

$\mathrm{u}_{\mathrm{p}}$, mean flow velocity at point

$\mathrm{p} ; \mathrm{u}^{*}$, friction velocity;

K, Von Karman constant;

E, empirical constant having a value of 9.81 ; 
$\mathrm{y}_{\mathrm{p}}$, distance from point $\mathrm{p}$ to the wall; and

$\Delta \mathrm{B}$, roughness function that depends, in general, on the wall roughness height, Ks.

At the inflow boundary, $\mathrm{u}$, the horizontal velocity component in the $\mathrm{x}$ direction, is given uniform velocity distribution. $\mathrm{v}$ and $\mathrm{w}$, the vertical velocity component in the $\mathrm{y}$ and $\mathrm{z}$ direction, is set to zero. At the outflow point of the reservoir, the horizontal velocity component is allocated a value to exactly balance inflow and the vertical velocity component is taken as zero. The initial velocity field into the reservoir is consisted of $x$ direction velocity, $\mathrm{u}$, and the other velocity, $\mathrm{v}$ and $\mathrm{w}$, are taken zero at all points except close to dam. The bottom and the free surface of the reservoir's temperatures are taken as adiabatic.

The initial temperature field consisted of a constant temperature throughout the reservoir. The dam face temperature is taken equal to the initial temperature of the reservoir water. The inflow river water temperature is set at a constant value with no variation over river depth. Reservoir temperature conditions will be changed later during the simulation run time. Therefore, initial temperature values are not of importance. In the turbulence model, the $\mathrm{k}$ and $\varepsilon$ were given a symmetry condition at the free surface same as the velocity condition.

\section{MODEL DESCRIPTION}

In order to examine diverging plunging flow in this study, the model is consisted to density diverging attached flow. Density flow has been studied with a sloping reservoir bottom both in width and longitudinal direction. Different inflow densimetric Froude numbers and diffuser half angles are taken and investigated herein. The inlet densimetric Froude numbers in all runs exceeded 1.0. Therefore, all runs indicate supercritical flow conditions. Density differences are generated using water of different temperatures for quiescent and inflow river water.

Basic model data are taken from the experimental data of Johnson and Stefan (1987 a-b, 1988). Schematic description of 3-dimensional model simulation for sloping dam reservoir is shown in Fig. 2. Dam reservoir length is 12,1 m., reservoir width is $5 \mathrm{~m}$., and $\delta$, divergence half angle; $\theta$, dam reservoir channel bottom slope; $\mathrm{H}$, depth of inflow channel; and $\mathrm{B}$, width of inflow channel in the model. All the parameters used in the model are given in Table 1. The cases correspond to experimental data of Johnson and Stefan (1987 a-b). In the Table 1, u0, mean inflow velocity; Qo, inflow discharge; To, inflow water temperature; Ta, ambient water temperature and Fo, is inflow densimetric Froude number. In the application, the densimetric Froude number, Fo, at reservoir inlet is defined as:

$$
F_{0}=\left(\frac{q^{2}}{g^{\prime} H^{3}}\right)^{\frac{1}{2}}
$$

where, $\quad g^{\prime}=g \Delta \rho / \rho o, g^{\prime}$, reduced acceleration of gravity;

$\Delta \rho=\rho-\rho 0, \Delta \rho$ is the density difference between ambient water and inflow river water,

$\rho$ is inflow river water density and $\rho$ o is ambient water density. 
Table 1. Inflow and Geometric Data using Model Simulation Runs

\begin{tabular}{|c|c|c|c|c|c|c|c|c|c|}
\hline Data & $\begin{array}{c}\boldsymbol{\delta} \\
(\mathbf{D e g})\end{array}$ & $\begin{array}{c}\boldsymbol{\theta} \\
(\mathbf{D e g})\end{array}$ & $\begin{array}{c}\mathbf{B} \\
(\mathbf{m})\end{array}$ & $\begin{array}{c}\mathbf{H} \\
(\mathbf{m})\end{array}$ & $\begin{array}{c}\mathbf{V} \\
(\mathbf{m} / \mathbf{s})\end{array}$ & $\begin{array}{c}\mathbf{Q}_{\mathbf{o}} \\
\left(\mathbf{m}^{\mathbf{3}} / \mathbf{s}\right)\end{array}$ & $\begin{array}{c}\mathbf{T}_{\mathbf{o}} \\
\left({ }^{\mathbf{}} \mathbf{C}\right)\end{array}$ & $\begin{array}{c}\mathbf{T}_{\mathbf{a}} \\
\left({ }^{\circ} \mathbf{C}\right)\end{array}$ & $\mathbf{F}_{\mathbf{o}}$ \\
\hline \multirow{2}{*}{ Case } & 20 & $\mathbf{1 , 5}$ & 0,17 & 0,091 & 0,116 & 0,0018 & 19,9 & $\mathbf{3 9 , 9}$ & $\mathbf{1 , 4 9}$ \\
\cline { 2 - 9 } & 20 & $\mathbf{3}$ & 0,17 & 0,091 & 0,116 & 0,0018 & 19,7 & $\mathbf{2 3 , 7}$ & $\mathbf{4 , 0 0}$ \\
\hline
\end{tabular}

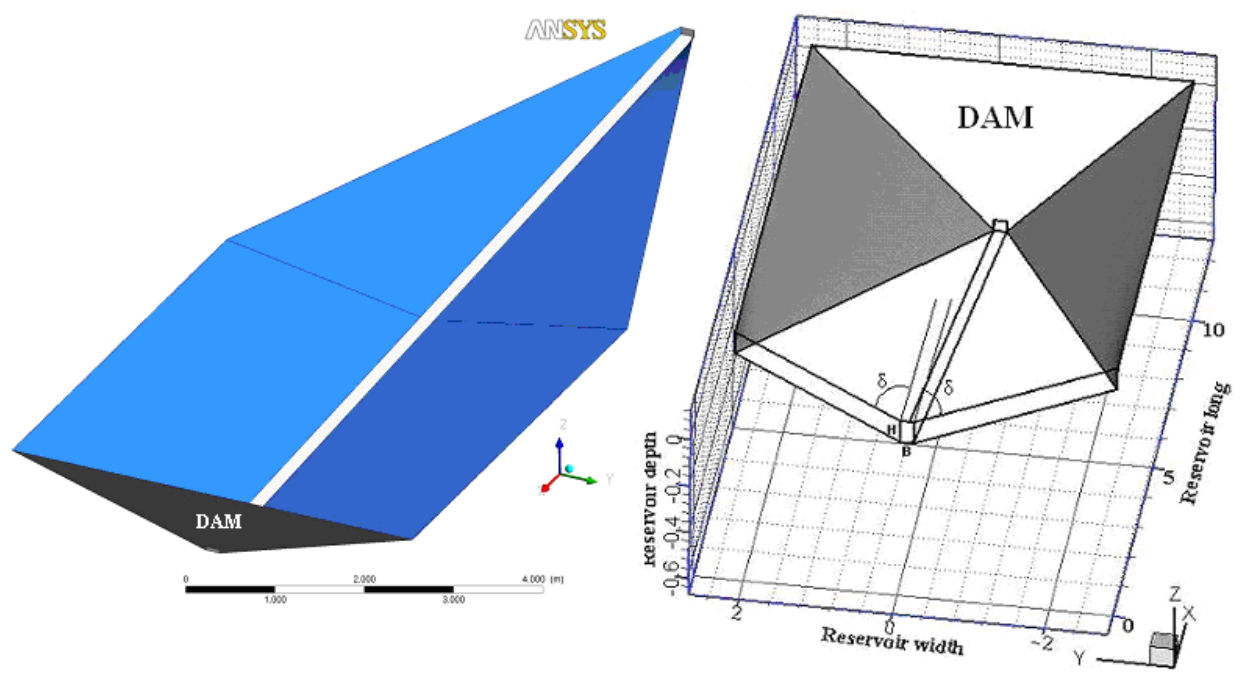

Fig. 2. Model Simulation Description for 3-Dimensional Sloping Dam Reservoir

In the model run, the reservoir is first filled with warm water as an initial condition, and then the cold water is released at the upstream end of the inflow channel at a specified discharge. The current proceeds forward until it reaches the downstream boundary. The calculation continued for approximately 1000 iterations at which point the front has long past the downstream boundary and any change in the flow field would be insignificant. The Application time is enough to see developing of underflow through the dam reservoir and any changing in the flow characteristic. In order to have the desired converged solution, a time step size of 10 seconds and maximum iteration per time step of 20 was chosen after preliminary trials.

\subsection{Model Results and Wall Attached Jet Flow $\left(10^{\circ}<\delta \leq 30^{\circ}\right)$}

Wall attached flows is defined and simulated for two different conditions as given condition of Table. 1 The model input parameters are based on experimental runs of Johnson et al (1987-b). Experimental results are given in Fig.3.

Density flow model developed in a similar manner as in the experimental works, as shown Figure 4. Reservoir thermocline contours fields on longitudinal crosssection are given in Fig. 4. In the figure, the density plunging flow and stratified forms occurs, and under flow and the ambient water moves towards the upstream through dam reservoir. First, the density plunging flow and stratified forms occurs 
and then, the ambient water moves uniformly upstream. In the meantime, ambient water is entrained laterally by the wall jet in the plunge region. In such cases, entrainment occurs near the water surface and through the recirculation region.

It can be seen from the experimental and obtained model result that if density current in a diffuser becomes attached to one wall "wall jet flow", a stalled circulation region will develop near the other one side of reservoir. Further away plunging flow occurs, and a stratified under flow forms. The ambient reservoir water moves upstream, and simultaneously, circulation flows occur on top of the underflow. As seen from the model simulation results, density current behavior depends on diffuser angle, reservoir channel bottom slope, the inflow densimetric Froude number, consequently, especially on reservoir inflow condition.

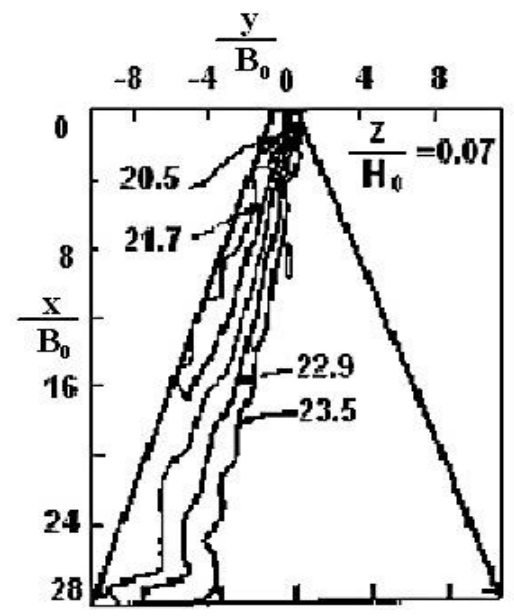

Fig. 3. Thermocline in diffuser at the different water depths obtained experimental result for $F_{o}=4, \delta=20^{\circ}$, and $\theta=3^{\circ}$ (Johnson et al., $1987 \mathrm{~b}$ )

As can be clearly seen from model simulation figures and the experimental works, density flow in the model is developed in a similar manner and distribution look in agreement with each other. First, the plunging occurs and under flow layer forms and then the ambient water moves uniformly upstream. Ambient water is entrained laterally by the wall jet in the plunge region. In such cases, entrainment occurs near the water surface and through the recalculating stalled region. And dilution is occurred in the underflow, as seen in Figure 4.

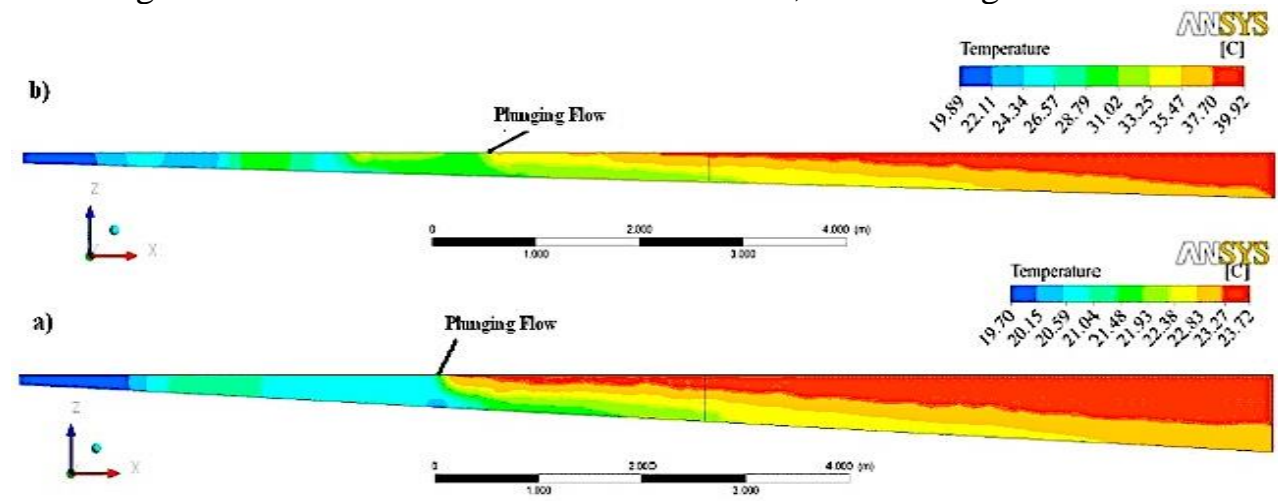

Fig. 4. Reservoir thermocline contours fields on longitudinal cross-section a) $\delta=20^{\circ}, \theta=3$ ${ }^{\circ}, F_{o}=4,00, T_{o}=19,7^{\circ} \mathrm{C}, \mathrm{T}_{a}=23,7^{\circ} \mathrm{C}$, b) $\delta=20^{\circ}, \theta=1.5^{\circ}, \mathrm{F}_{\mathrm{o}}=1,49, \mathrm{~T}_{0}=19,9^{\circ} \mathrm{C}, \mathrm{T}_{a}=39,9^{\circ} \mathrm{C}$ 
As can be understood in simulation figures, if density current in a diffuser becomes attaches to one wall, a stalled region will develop near the other one. Further away plunging flow occurs, and a stratified under flow forms. The ambient water moves upstream and circulation flows occur on top of the underflow. Figure 5, 6 and 7 show typical attached flow in the $20^{\circ}$ (middle) half angles diffuser.

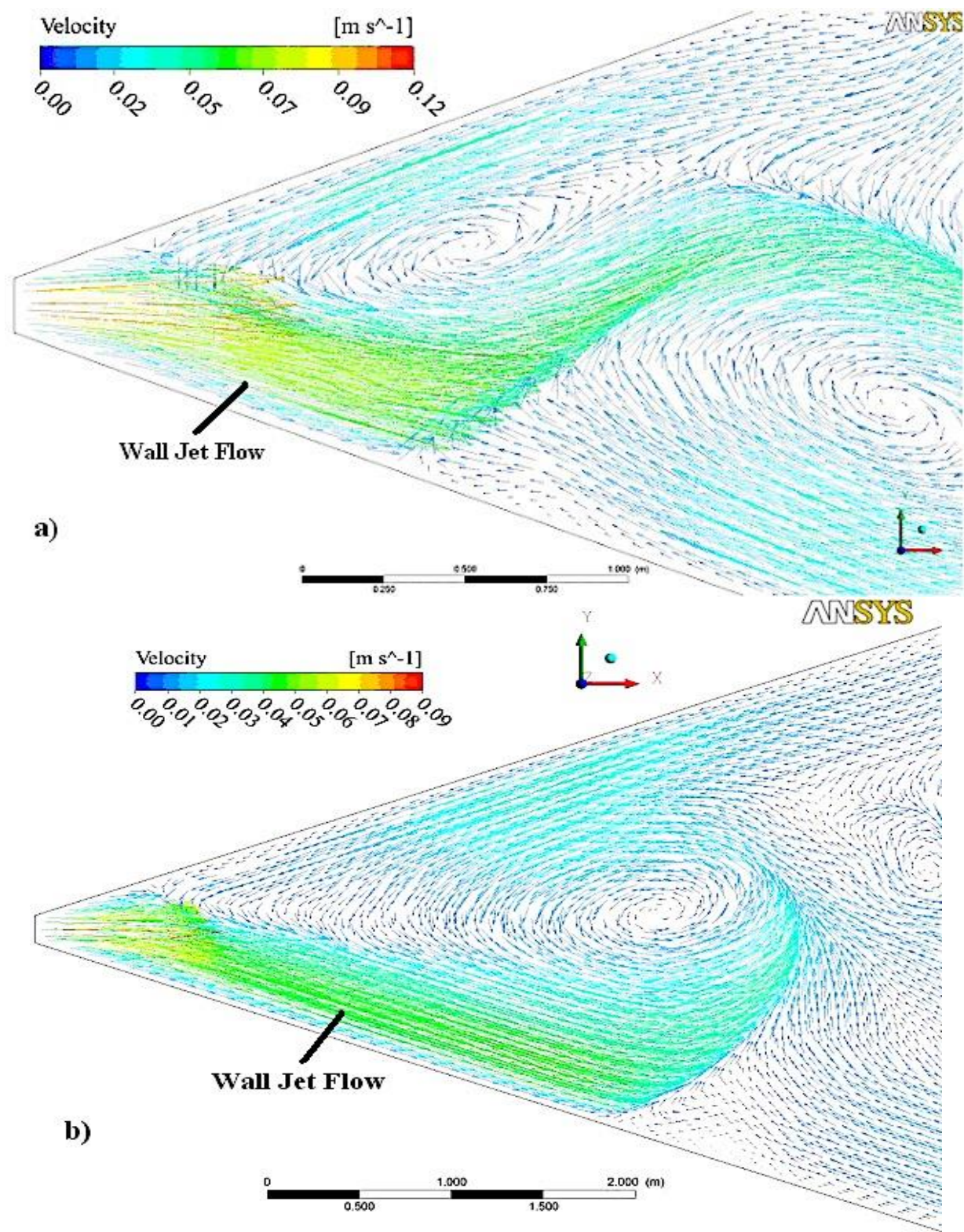

Fig. 5. Typical reservoir velocity vectors cross-section views for overall water surface a) Elapsed time is 500 seconds, $\left.\delta=20^{\circ}, \theta=1.5^{\circ}, F_{o}=1,49, T_{o}=19,9^{\circ} \mathrm{C}, T_{a}=39,9^{\circ} \mathrm{C}, \mathrm{b}\right)$ Elapsed time is 800 seconds, $\delta=20^{\circ}, \theta=3^{\circ}, F_{o}=4,00, T_{o}=19,7^{\circ} \mathrm{C}, T_{a}=23,7^{\circ} \mathrm{C}$ 
In these figures, separations from one side wall of reservoir appear and this type of divergence flow is named wall attached jet flow.

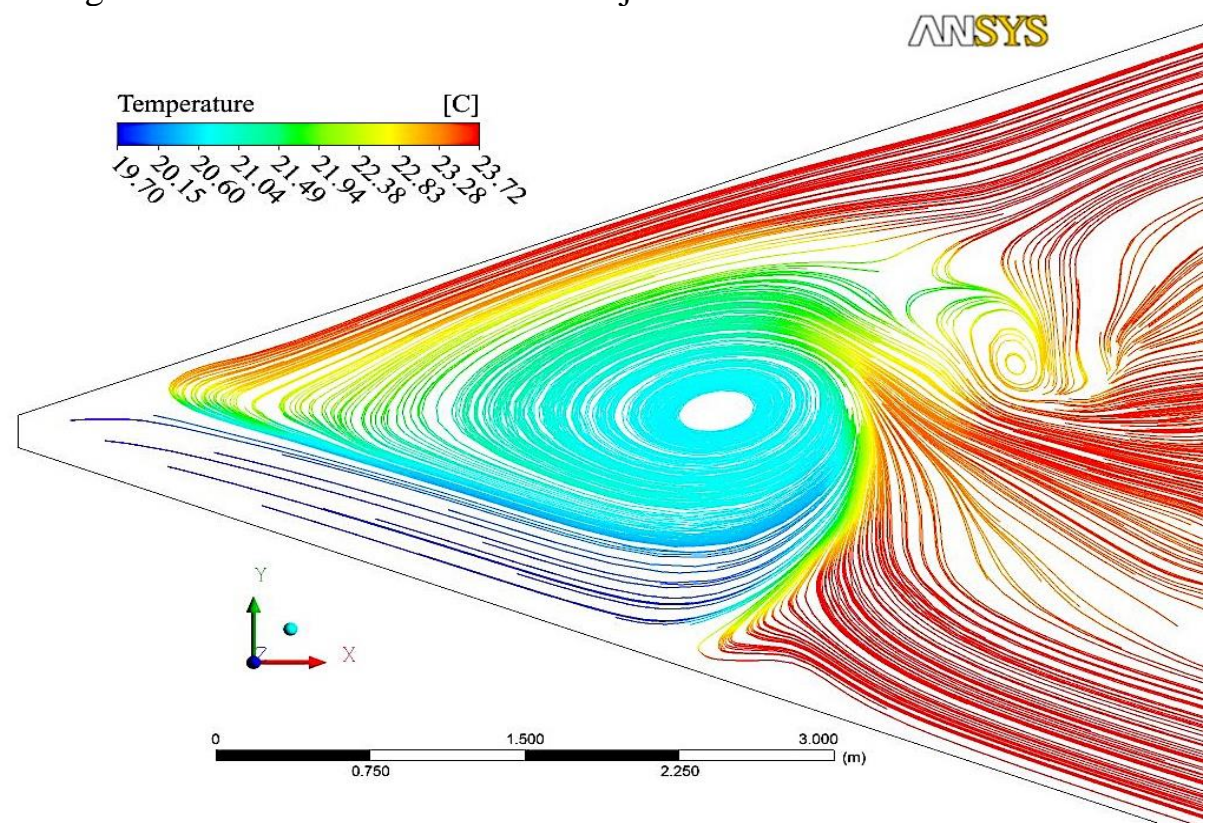

Fig. 6. Reservoir thermocline at the water surface, Elapsed time is 800 seconds, $\delta=20^{\circ}$, $\theta=3^{o}, F_{o}=4,00, T_{o}=19,7^{\circ} \mathrm{C}, T_{a}=23,7^{\circ} \mathrm{C}$

Wall jet flow, stall formation and velocity variation can clearly be defined from simulation figures. Fig. 5 (a), and (b) show typical velocity field vector for the defined case on the enlarged plunging surface plan region. The figures show reservoir velocity vectors field section on the water surface at the elapsed time of 500 and 800 seconds. Wall jet flow, stall formation and velocity variation can clearly be defined from these figures.

Fig. 6 and 7 show typical reservoir thermocline field for $\delta=200, \theta=3 \mathrm{o}, \mathrm{Fo}=4,00$, $\mathrm{To}=19,7 \mathrm{oC}, \mathrm{Ta}=23,7 \mathrm{oC}$ and $\delta=20 \mathrm{o}, \theta=1.5 \mathrm{o}, \mathrm{Fo}=1,49, \mathrm{To}=19,9 \mathrm{oC}, \mathrm{Ta}=39,9 \mathrm{oC}$ at the water surface at the elapsed time of 800 seconds, respectively. The model results are substantially consistent with experimental results. Wall jet flow, stall formation and thermal variation can clearly be defined from the model water surface thermocline figures.

\section{CONCLUSIONS}

Three-dimensional mathematical model including Coriolis force was used to investigate the density flow and wall jet flow in a diverging channel with a dam reservoir with sloping bottom. The river inflow was simulated along the reservoir in three dimensions mathematical model. Attached wall-jet flow in diverging channel with a sloping was investigated. In addition to these, plunging parameters and plunging phenomenon was also investigated. Simulation results show that when diffuser angle 
is between $10 \mathrm{o}$ to $40 \mathrm{o}$, one wall jet flow and circulation area is occurred in reservoir surface. Model and experimental results were found to be compatible.

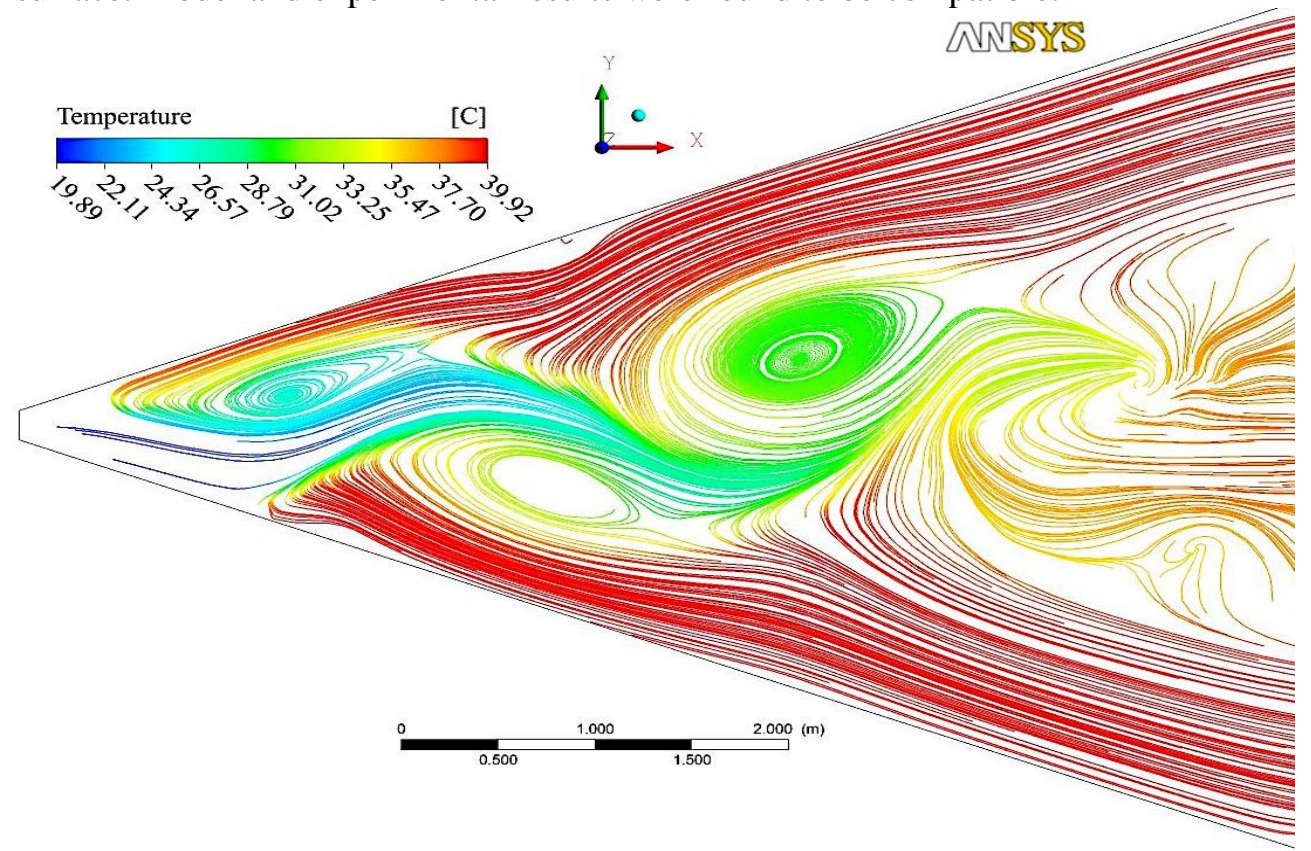

Fig. 7. Reservoir thermocline at the water surface, Elapsed time is 800 seconds, $\delta=20^{\circ}$, $\theta=1.5^{\circ}, F_{o}=1,49, T_{o}=19,9^{\circ} \mathrm{C}, \mathrm{T}_{a}=39,9^{\circ} \mathrm{C}$

\section{REFERENCES}

1. Alavian, V. (1986) Behavior of Density Current on an Incline, J. Hydr. Engrg., ASCE, $112,27-42$.

2. Akiyama, J., Stefan, G.H. (1984) Plunging Flow into a Reservoir: Theory, Journal of Hydraulic Engineering, ASCE, 110, 484-489.

3. Bournet, P.E., Dartus, D., Tassin, B., Vincon-Leite, B. (1999) Numerical Investigation of Plunging Density Current, Journal of Hydraulic Engineering, ASCE, 125, 584-594.

4. Farrell, G.J., Stefan, H. G. (1988) Mathematical Modeling of Plunging Reservoir Flows, Journal of Hydraulics Research, 26, 525-537.

5. Farrell, G.J., Stefan, H.G. (1988), Buoyancy Induced Plunging Flow into Reservoirs and Coastal Regions, Project Report, No. 241, St. Anthony falls Hydr. Lab., University of Minnesota.

6. ANSYS FLUENT users Guide, ANSYS FLUENT incorporated, 2012.

7. Fukushima, Y., Watanabe, M., (1990) Numerical Simulation of Density Underflow by the $k$ - $\varepsilon$ Turbulence Model, J. Hydroscl. Hydr. Eng., 8, 31-40.

8. Johnson, T.R., Farrell, G.J., Ellis, C.R., Stefan, H.G., (1987a), Negatively Buoyant Flow in Diverging Channel: Part I: Flow Regimes, Journal Hydraulic Engineering, ASCE, 113, 716-730. 
9. Johnson, T.R., Ellis, C.R., Stefan, H.G., (1987b), Negatively Buoyant Flow in Diverging Channel: Part II: 3-D Flow Field Regimes, Journal Hydraulic Engineering, ASCE, 113, 731-742.

10. Johnson, T.R., Stefan, H.G., (1988), Experimental Study of density induced plunging flow into reservoirs and coastal regions, Project Report, No. 245, St. Anthony falls Hydr. Lab., University of Minnesota.

11. Kassem A., Imran, J., (2001), Simulation of Turbid Underflows Generated by the Plunging of a River, Geology, 29(7), 655-658.

12. Kassem, A., Imran, J., Khan, J.A., (2003), Three-Dimensional Modeling of Negatively Buoyant Flow in Diverging Channels. Journal Hydraulic Engineering, 129 (12), 936947.

13. Launder, B.E., Spalding, D.B. (1972), Mathematical models of Turbulence, Academic Press, New York.

14. Launder, B.E., Spalding, D.B., (1974), The Numerical Computation of Turbulent Flows, Computer Methods in Applied Mechanics and Engineering, 3, 269-289.

15. Patankar, S.V., (1980), Numerical Heat Transfer and Fluid Flows, McGraw-Hill, New York.

16. Patankar, S.V., Spalding, D.B., (1972), A Calculation Procedure for Heat, Mass and Momentum Transfer in Three Dimensional Parabolic Flows, International Journal Heat and Mass Transfer, 15. s.1787.

17. Rodi, W., (1980). Turbulence Models and their Application in Hydraulics, Report. Int. Assoc. for Hydraul. Res., Delft, Netherlands.

18. Rodi, W., (1987), Example of calculation methods for flow and mixing in stratified fluids, J. Geophys. Res., 92, 5305-5328.

19. Singh, B., Shah, C.R., (1971), Plunging Phenomenon of Density Currents in Reservoirs, La Houille Blanche, 26, 59-64.

20. Savage, S.B., Brimberg, J., (1975), Analysis of Plunging Phenomena in Water Reservoirs, J. Hydr. Res., 13(2), 187-204.

21. Üneş, F., (2004), Investigation of Effects of Coriolis Forces and Outlet Levels on Reservoir Flow Using Mathematical Model, Istanbul Technical University, Ph.D. Dissertation, Institute of Science and Technology, Istanbul

22. Üneş, F., (2005), Investigation of Temporary Variation of Plunging Point Caused by Density Plunging Reservoir Flow Using Mathematical Modeling, Digest 2005, Turkish Chamber of Civil Engineers, Technical Journal.

23. Üneş, F., Ağıralioğlu, N., (2004), Investigation Of Density Plunging Reservoir Flow Using Mathematical Modeling, İTÜ Journal, 1/d, (3)(6), Turkish.

24. Varçin, H., Üneş, F., (2008), Investigation of density flows in Ĕgrekkaya dam reservoir by three-dimensional Mathematical Model, CU Faculty of Engineering and Architecture 30th Year Symposium, Adana, Turkey

25. Üneş F., (2008a), Analysis of plunging phenomenon in dam reservoirs using threedimensional density flow simulations, Canadian Journal of Civil Engineering, 35, 1138-1151.

26. Üneş F., (2008b), Investigation of density flow in dam reservoirs using a threedimensional mathematical model including Coriolis effect, Computers \& Fluids, 37, 1170-1192.

27. Üneş F., (2009), Investigation of Flows into a Real Dam Reservoir Using ThreeDimensional Mathematical Model, Project Report, No. 106Y294.

28. Üneş F., (2010), Prediction of density flow plunging depth in dam reservoirs: an artificial neural network approach, Clean - Soil, Air, Water, 38, 296-308. 
29. Üneş F., Varcin H., Demirci M., (2012), Investigation Of Monthly Density Flow In A Real Dam Reservoir Using Mathematical Model, VII th 7th National Hydrology Congress, 128-138, Isparta, Turkey.

30. Üneş F., Varcin H., (2012), Investigation of plunging depth and density currents in Egrekkaya Dam Reservoir, Turkish Chamber of Civil Engineers, Technical Journal, 367, 5725-5750.

31. Üneş F., Varcin H., (2015), Investigation of seasonal thermal flow in real dam reservoir using 3 D numerical modeling, Journal of Hydrology and Hydromechanics,63(1), 38-46.

32. Üneş, F., Demirci, M., Varçin, H., (2016), 3-D Numerical Simulation of a Real Dam Reservoir: Thermal Stratified Flow. Advances in Hydroinformatics, pp. 377-394, Springer, Singapore.

33. Üneş, F., Joksimovic, D., Kisi, O., (2017), Plunging flow depth estimation in a stratified dam reservoir using neuro-fuzzy technique. Water resources management, 29(9), 3055-3077.

34. Üneş F., Varcin H., (2017), 3 D Real Dam Reservoir Model for Seasonal Thermal Density Flow, Environmental Engineering and Management Journal, 16(9), 20092024.

35. Üneş F., Ağıralioğlu, N., (2017), Numerical Investigation of Temporal Variation of Density Flow and Parameters, Journal of Applied Fluid Mechanics, 10(1), 81-94. 